\title{
Evidence based guidelines for the prevention, identification, and management of occupational asthma
}

\section{S M Tarlo, G M Liss}

\section{Commentary on the paper by Nicholson et al (see page 290)}

$\mathrm{T}$ he article by Nicholson et al in this issue of $O E M$ has an ambitious aim: to assist the Health and Safety Executive in the reduction of occupational asthma by $30 \%$ in the next five years. ${ }^{1}$ The article is very well written and timely. Occupational asthma (OA) as noted by the authors is the most common chronic occupational lung disease now in most industrialised countries and most reported rates have not shown a decline in recent years. However, it is not clear as to what database will be used (both to establish baseline incidence and in the future) to determine changes in incidence of OA which may result from these guidesthe SWORD scheme, compensation claims, or a new database?

Is there knowledge which could be implemented to produce a decline of the magnitude stated? Preventive measures for $\mathrm{OA}$ designated by the authors as having a hypersensitivity cause, have been well described, and recently reviewed..$^{3}$ Primary prevention can have dramatic effects when it is feasible. It can be achieved by preventing the exposures which lead to sensitisation and asthma. When an allergenic agent can be removed from a workplace, be substituted with a safe alternative, or be completely enclosed so that inhalation exposure does not occur, then rates of occupational asthma from that allergen in that setting should fall by $100 \%$. This has been the observation when natural rubber latex (NRL) gloves are replaced in healthcare settings with non-NRL gloves, and also when enzymes in a workplace are encapsulated as part of a controlled programme. Even when exposure is markedly reduced, such as use of NRL gloves which have a low protein content and are powder-free, NRL occupational asthma rates fall to close to zero. Similarly estimates have been made for air concentrations of wheat (and

enzyme additives to flour), below which bakers' asthma is not expected to occur except in those with very high underlying susceptibility. Therefore when this is feasible in a workplace environment, primary prevention is the best choice for intervention. Even when complete avoidance is not possible, and reduction of levels to non-sensitising concentrations cannot be achieved, significant reduction of levels should reduce the risk of sensitisation and OA based on the knowledge that the risk of $\mathrm{OA}$ has some dose-response relation.

As indicated by the authors, it is often difficult to quantify the reduction in rates of OA by a partial reduction in exposure (as obtained by use of personal protective equipment, enclosure of the agent, improved ventilation or reduced use of a sensitiser), since such measures are often introduced at the same time as secondary preventive measures such as medical surveillance and worker education. A further complicating issue is that there may be importance to peaks of sensitiser exposure which may not be captured by usual workplace monitoring, and therefore it may be difficult to determine whether control measures to reduce exposure are also reducing peaks of exposure. Further research is needed to better define the types of exposure most likely to sensitise and cause OA, but this should not delay the implementation of exposure controls for workplace sensitisers as far as is practical, as recommended in this report.

Similarly, although the level of evidence to support the implementation of medical surveillance for secondary prevention of OA lacks rigorous scientific evidence, and is classified by the authors as ${ }^{* *}$ SIGN $2+$ or *SIGN 3 evidence, we are supportive of the authors' conclusions that this now be recommended in workplaces where there is exposure to potential sensitisers, since prospective double blind controlled trials of such intervention without the addition of other measures such as exposure controls and worker education, would be difficult to implement, in part due to ethical considerations. Nevertheless, it would be extremely helpful to perform prospective assessments after implementation of medical surveillance programmes and other preventive workplace measures to obtain some measures of effectiveness. Also of interest will be information as to the proposed implementation of the programme-will this be by a legislative requirement versus voluntary implementation; and at what threshold of increased asthma risk will the programme be introduced in a workplace?

How practical are medical surveillance programmes for OA? Our experience of the diisocyanate medical surveillance programme in Ontario, suggesting overall benefit of the programme is based on retrospective evaluations. ${ }^{4-7}$ Some difficulties with this programme include: difficulty in assessing compliance with the programme in small workplaces (such as small auto body shops spray painting cars); lack of a company physician for medical surveillance in small workplaces; choice of workers to undergo medical assessments from their own physicians rather than in a standardised manner by a company physician; a shortage of government employees to ensure compliance with workplace exposure levels; and the practice of notifying a company prior to a worksite visit to assess compliance. Despite these difficulties the diisocyanate programme in Ontario has been associated with significant reductions in the incidence of diisocyanate OA, as well as earlier diagnosis, milder asthma at the time of diagnosis, and reduced risk of hospitalisation, ${ }^{8}$ compared with those with OA due to other causes, suggesting overall benefit. However, in Ontario, many diisocyanate using companies are large producers of polyurethane foam for which medical surveillance measures and exposure controls could be more easily introduced than in smaller companies.

An additional component to enhance early diagnosis may be provision of effective education to workers and their primary care physicians in order to suspect the diagnosis of work related asthma early and have early investigation of this as recommended by the authors. Preliminary studies have suggested that delay in diagnosis is more likely to occur in those workers with less formal schooling and a lower income," suggesting that these workers may need 
additional or different education and attention in the workplace about the manifestations of work related asthma and the action to take if symptoms occur.

The Guidelines also comment on the appropriate investigation of those suspected to have occupational asthma. Many of the recommendations are similar to those addressed in previous guidelines such as those from the Canadian Thoracic Society. ${ }^{10}$ However, a significant difference is the interpretation of a normal methacholine response "within 24 hours of exposure" to the suspected workplace agent, which in the current document is considered to have a low predictive value for exclusion of occupational asthma. This is quite different from the interpretation in previous reports which have considered that a normal response within 24 hours after exposure to a suspected work sensitiser has a high predictive value in excluding OA. ${ }^{10}{ }^{11}$ While there are many reports of normal airway responsiveness in those with occupational asthma when the test is performed after a period away from exposure and within 24 hours prior to return to the workplace exposure or to a laboratory exposure challenge, the number of cases reported where a normal methacholine or histamine response occurred within 24 hours after a positive work or chamber specific challenge is very low. Indeed, it has been suggested that development of an increase in nonspecific airway hyper-responsiveness following a specific challenge exposure to an occupational sensitiser is a more sensitive marker than spirometric changes. ${ }^{12}$ Thus when a patient is seen at a time when they are still working with exposure to the suspected sensitiser and still have work related asthma symptoms, then a methacholine challenge within 24 hours after exposure to the suspected work sensitiser is useful, as a normal response at that time has a high predictive value in excluding
OA, similar to the interpretation in asthma which is not occupational as reviewed in the American Thoracic Society guidelines for methacholine and exercise testing. ${ }^{13}$ This also emphasises the importance of keeping the patient at work if possible while diagnostic tests are performed (which is not specifically mentioned by the authors) since other than specific skin testing or challenge with the suspected sensitiser, tests to confirm or refute the diagnosis are difficult to initiate after a patient has moved to a different workplace. In addition, exposure assessment and review by the examining physician of relevant material safety data sheets (MSDSs) from the workplace, which were not discussed in this document, can help in determining the presence of an occupational sensitiser, but may be more difficult to accomplish after the patient has left the workplace since it may be harder to obtain the MSDSs.

Finally, there is a need for physicians to assist their patients with appropriate compensation claims, and a need to liaise with appropriate agencies (company physicians, government organisations), to ensure that other co-workers are considered when a diagnosis of OA is made, since this should be considered as a "sentinel event" as suggested in other guidelines. Such notification (either anonymously with respect to naming the worker or within limits of the patient's privacy) may enhance preventive measures in that workplace, enhance consideration of possible coworkers who may also be at risk, and allow detection of any lapses which may have contributed to sensitisation and OA.

We look forward to the implementation of the Guidelines and a reduction in the burden of illness due to OA.

Occup Environ Med 2005;62:288-289 doi: 10.1136/oem.2004.019539

\section{Authors' affiliations}

S M Tarlo, University of Toronto, Departments of Medicine and Public Health Sciences, Gage Occupational and Environmental Health Unit, Toronto Western Hospital, Canada

G M Liss, University of Toronto, Public Health Sciences, Gage Occupational and

Environmental Health Unit, Ontario Ministry of Labour, Canada

Correspondence to: $\operatorname{Dr}$ S M Tarlo, Toronto Western Hospital, East Wing 7-449, 399 Bathurst St, Toronto, M5T 2S8, Canada; susan. tarlo@utoronto.ca

Competing interests: none

\section{REFERENCES}

1 Nicholson PJ, Cullinan P, Newman Taylor AJ, ef al. Evidence based guidelines for the prevention, identification, and management of occupational asthma. Occup Environ Med 2005:62:290-9.

2 Cullinan P, Tarlo S, Nemery B. The prevention of occupational asthma. Eur Respir J 2003:22:853-60.

3 Tarlo SM, Liss GM. Can medical surveillance measures improve the outcome of occupational asthma? J Allergy Clin Immunol 2001; 107:583-5.

4 Tarlo SM, Liss GM, Yeung KS. Changes in rates and severity of compensation claims for asthma due to diisocyanates: a possible effect of medical surveillance measures. Occup Environ Med 2002;59:58-62.

5 Kraw M, Tarlo SM. Isocyanate medical surveillance: respiratory referrals from a foam manufacturing plant over a five-year period. Am J Ind Med 1999;35:87-91.

6 Tarlo SM, Banks D, Liss G, et al. Outcome determinants for isocyanate induced occupational asthma among compensation claimants. Occup Environ Med 1997:54:756-61.

7 Tarlo SM, Liss GM, Dias C, et al. Assessment of the relationship between isocyanate exposure levels and occupational asthma. Am J Ind Med 1997:32:517-21.

8 Liss GM, Tarlo SM, Macfarlane $Y$, et al. Hospitalization among workers compensated for occupational asthma. Am J Respir Crit Care Med 2000; 162:112-18.

9 Poonai NP, van Diepen SF, Bharatha A, et al. Barriers to diagnosis of occupational asthma. Can $J$ Public Health. In press.

10 Tarlo SM, Boulet LP, Cartier A, et al. Canadian Thoracic Society Guidelines for occupational asthma Can Respir J 1998.5:289-300.

11 Moscato G, Malo JL, Bernstein D. Diagnosing occupational asthma: how much, how far? Eur Respir J 2003;21:879-85.

12 Vandenplas O, Malo JL. Inhalation challenges with agents causing occupational asthma. Eur Respir J 1997; 10:2612-29.

13 American Thoracic Society. Guidelines for methacholine and exercise challenge testing 1999. Am J Respir Crit Care Med 2000;161:309-29.

(1) a; (2) d; (3) b; (4) a; (5) c 